\title{
Ação do extrato metanólico e etanólico de Davilla elliptica St. Hil. (Dilleniaceae) na resposta imune
}

\author{
I.Z. Carlos $^{1 *}$, F.C.M. Lopes ${ }^{1}$, F.P. Benzatti', C.B.A. Carli, M.F. Marques ${ }^{1}$, C.M. Jordão \\ Junior ${ }^{2}$, D. Rinaldo ${ }^{3}$, T.R. Calvo ${ }^{3}$, L.C. Santos ${ }^{3}$ W. Vilegas ${ }^{3}$ \\ ${ }^{1}$ Departamento de Análises Clínicas, Faculdade de Ciências Farmacêuticas, Universidade Estadual Paulista, Caixa \\ Postal 502, 14801-902, Araraquara, SP, Brasil, \\ ${ }^{2}$ Departamento de Ciências Biológicas, Faculdade de Ciências Farmacêuticas, Universidade Estadual Paulista, \\ 14801-902, Araraquara, SP, Brasil, \\ ${ }^{3}$ Departamento de Química Orgânica, Instituto de Química, Universidade Estadual Paulista, Caixa Postal 355, \\ 14801-970, Araraquara, SP, Brasil.
}

Muitas plantas usadas na medicina tradicional demonstraram modular a resposta imunológica (Agarwal; Singh, 1999). Davilla elliptica St. Hil. (Dilleniaceae) é uma árvore pequena que cresce no cerrado do Brasil. Esta planta, conhecida como Cipó-caboclo e Pau-debugre, é utilizada como tônico, adstringente e laxante por populações locais (Rodrigues et al, 2002; Rodrigues; Carvalho, 2001).

Nota: Errata publicada em correção ao trabalho original publicado no primeiro fascículo do volume 15 da Revista Brasileira de Farmacognosia. No trabalho original, o nome da família vegetal aparecia como Malpighiaceae, ao invés de Dilleniaceae, como é o correto. 